\title{
Two-year longitudinal change in choroidal and retinal thickness in school-aged myopic children: exploratory analysis of clinical trials for myopia progression
}

Meiping $X u^{1,2}$, Xinping $Y u^{1,2}$, Minghui Wan ${ }^{1,2}$, Kemi Feng ${ }^{1,2}$, Junxiao Zhang ${ }^{1,2,3}$, Meixiao Shen ${ }^{1,2}$, Björn Drobe ${ }^{3,4}$, Hao Chen ${ }^{1,2}$, Jia $\mathrm{Qu}^{1,2^{*}}$ and Jinhua Bao ${ }^{1,2,3^{*}}$ (])

\begin{abstract}
Background: With increasing axial length and myopia progression, the micro-structure of the retina and choroid gradually changes. Our study describes the longitudinal changes in retinal and choroidal thickness in school-aged children with myopia and explores the relationship between changes in choroidal thickness and myopia progression.

Methods: An exploratory analysis of a randomized trial was performed. Children ( $n=168$, aged 7 to 12 years) with myopia from -0.75 dioptre (D) to $-4.00 \mathrm{D}$ were enrolled in this prospective longitudinal study. Cycloplegic refraction, axial length (AL), retinal and choroidal thicknesses were measured at baseline and at 1- and 2-year follow-ups. "Rapid progression myopia" was defined as increasing in myopia $>1.00 \mathrm{D}$ and "stable progression myopia" was $\leq 1.00$ $D$ during the 2-year follow-up. Factors affecting the changes in choroidal thickness were analysed using linear mixed models.
\end{abstract}

Results: AL significantly increased by $0.67 \pm 0.24 \mathrm{~mm}$ with a myopic shift of $-1.50 \pm 0.64 \mathrm{D}$ over the 2 years. The overall retinal thickness increased from $251.12 \pm 15.91 \mu \mathrm{m}$ at baseline to $253.47 \pm 15.74 \mu \mathrm{m}$ at the 2-year followup $(F=23.785, P<0.001)$. The subfoveal choroidal thickness decreased from $231.03 \pm 54.04 \mu \mathrm{m}$ at baseline to $206.53 \pm 59.71 \mu \mathrm{m}$ at the 2 -year follow-up $(F=73.358, P<0.001)$. Choroidal thinning was significantly associated with AL elongation $(\beta=-43.579 \mu \mathrm{m} / \mathrm{mm}, P=0.002)$ and $\operatorname{sex}(\beta=-17.258, P=0.001)$. Choroidal thickness continued to decrease in subjects with rapid progression $(F=92.06, P<0.001)$ but not in those with steady progression $(F=2.23$, $P=0.119$ ).

Conclusion: Significant choroidal thinning was observed and was associated with rapid progression and sex. These findings indicate a need to understand the role of the choroid in eye growth and myopia development.

Synopsis/Precis: The macular choroidal thickness of myopic children is relevant to different degrees of myopic progression in this 2-year longitudinal study. These findings suggest that control of choroidal thickness might work to regulate human ocular growth.

Trial registration Chinese Clinical Trial Register (ChiCTR): ChiCTR-INR-16007722

*Correspondence: jia.qu@163.com; baojessie@163.com

1 Eye Hospital and School of Ophthalmology and Optometry, Wenzhou Medical University, Wenzhou, Zhejiang, China

Full list of author information is available at the end of the article

(C) The Author(s) 2022. Open Access This article is licensed under a Creative Commons Attribution 4.0 International License, which permits use, sharing, adaptation, distribution and reproduction in any medium or format, as long as you give appropriate credit to the original author(s) and the source, provide a link to the Creative Commons licence, and indicate if changes were made. The images or other third party material in this article are included in the article's Creative Commons licence, unless indicated otherwise in a credit line to the material. If material is not included in the article's Creative Commons licence and your intended use is not permitted by statutory regulation or exceeds the permitted use, you will need to obtain permission directly from the copyright holder. To view a copy of this licence, visit http://creativecommons.org/licenses/by/4.0/. The Creative Commons Public Domain Dedication waiver (http://creativeco mmons.org/publicdomain/zero/1.0/) applies to the data made available in this article, unless otherwise stated in a credit line to the data. 
Keywords: Axial length, Choroidal thickness, Children, Myopia, Spectral-domain optical coherence tomography

\section{Background}

Myopia is widely perceived as a global issue, with the incidence rate increasing year by year, especially in Asian countries [1-3]. While the underlying pathogenesis of myopic development is still elusive, the effectiveness of interventions for myopia prevention and control is limited. Previous animal experimental studies [4-6] confirmed that the choroid might play an important role in refractive adjustment and eye growth. The eye can detect retinal myopic defocus (image-focused in front of the retina), or hyperopic defocus (imagefocused behind the retina) and undergo compensatory growth by increasing or decreasing choroidal thickness $(\mathrm{CT})$. Thus, CT changes precede axial length changes and scleral remodelling $[5,7]$. The change in subfoveal CT could be related to changes in choroidal blood flow $[8,9]$, lymphatics [10], nonvascular smooth muscle [11] and choroidal vascularity index $[12,13]$. Zhou and colleagues found that changes in CT were positively correlated with changes in choroidal blood flow in guinea pig myopia [14] and increased choroidal blood flow attenuates scleral hypoxia as well as inhibits myopia development [15]. In addition, clinical studies also found significantly decreased CT and choroidal blood perfusion after near work, which is a risk factor for myopia [16-18]. Such decreased choroidal blood perfusion might cause scleral hypoxia.

Morphological analysis of the fundic retina and choroid depends on acquiring clear optical coherence tomography (OCT) images and segmentation of the posterior segment layers either manually or by computer programs that automatically or semi-automatically identify the layer interfaces. Previous studies have revealed the clinical characteristics of subfoveal $\mathrm{CT}$ and associated factors such as age, sex, birth parameters, puberty, ethnicity, refractive dioptre (D), and axial length (AL) [19-22]. Some cross-sectional studies have found that CT may increase during childhood and become the thickest during adolescence [20, 23, 24]. CT has been shown to be thinner in myopes than in hyperopes and even thinner in high myopes $[25,26]$. There are relatively few longitudinal studies, even then their conclusions are somewhat controversial. Hansen et al. confirmed that the CT of children aged 11 to 16 increased, while the increase was greater in hyperopes and lesser in myopes [27]. Jin et al. demonstrated CT reduction in those who developed myopic shift [28]. Xiong et al. found a marked decrease in $\mathrm{CT}$ in patients with newly developed myopia but not in those with persistent myopia [29]. Such divergent findings may be related to ethnic differences, different age ranges, and different refractive power changes.

Recent studies have suggested that choroidal thinning occurs in the early period of myopic development $[29,30]$, but age-related changes in myopic choroidal thinning and the association with myopic progression have not been established quantitatively. The main purpose of this 2-year longitudinal study was to observe the nature and time course of changes in $\mathrm{CT}$ in children aged 7 to 12 years with low-to-moderate myopia $(-0.75$ to $-4.00 \mathrm{D})$. A second goal was to explore factors that affect the changes in CT in myopic children as well as the potential role of the choroid in myopia progression.

\section{Materials and methods}

\section{Setting and participants}

This prospective, longitudinal study was conducted according to the tenets of the Declaration of Helsinki. It was approved by the Institutional Review Board of the Eye Hospital of Wenzhou Medical University. After the participants understood the study protocol and possible consequences of the study, consent was obtained from the participating children and their parents or other guardians.

This study was a part of the Personalized Addition Lenses Clinical Trials (PACT) [31], which was a randomized clinical trial to determine if myopia progression is different between children wearing personalized progressive addition lenses (PPALs) versus $+2.00 \mathrm{D}$ fixed progressive addition lenses (FPALs) or single vision lenses (SVLs). The study was registered in the Chinese Clinical Trial Register (ChiCTR, ChiCTR-INR-16007722). The inclusion criteria were as follows: children with age 7 to 12 years and spherical equivalent of refraction (SER) between -4.00 and $-0.75 \mathrm{D}$ as measured by cycloplegic autorefraction in both eyes. The participants were excluded for the following reasons: best-corrected visual acuity (BCVA) less than 20/25, anisometropia $>1.0 \mathrm{D}$ in SER, history of intraocular surgery, or ocular comorbidities, including strabismus.

\section{Research methods}

The children $(\mathrm{n}=210)$ were enrolled from the Optometry Clinic of the Eye Hospital of Wenzhou Medical University from July 1, 2014, to February 1, 2015. Essential information included sex, age, time of occurrence of 
myopia, birth history, and refractive status of their parents. Each child was randomly assigned to wear either PPALs, FPALs, or SVLs.

The enrolled participants were followed up every 6 months for 2 years, and underwent comprehensive ophthalmic examinations, including BCVA, cycloplegic refraction, anterior segment, fundus examination [including spectral-domain optical coherence tomography (SD-OCT) to measure the thickness of the choroid and retina], and AL. These tests were performed at each follow-up visit, except for SD-OCT, which was performed once a year. After corneal anaesthesia was induced with one drop of proparacaine (0.5\% Alcaine, Alcon Laboratories, Ft. Worth, TX, USA), cycloplegia was achieved by administering three drops of $1 \%$ cyclopentolate (Alcon Laboratories) $5 \mathrm{~min}$ apart. Five consecutive and reliable autorefraction (Canon RK-F1; Canon Inc., Tokyo, Japan) measurements were obtained $30 \mathrm{~min}$ after the third drop was administered. There were conflicting reports regarding the influence of cyclopentolate on the $\mathrm{AL}$ and $\mathrm{CT}$ [32-35]. To obtain high quality SD-OCT images and consistent results, the AL and SD-OCT were measured after cycloplegic autorefraction in this study. SER was used to classify the refractive status. AL was measured by a Lenstar LS900 (Haag-Streit AG, Koeniz, Switzerland).

\section{SD-OCT procedure and data collection}

All participants underwent a macular scan using the Cirrus 4000 HD-OCT (Zeiss, Oberkochen, Germany) with the macular radial $512 \times 128$ cube scan pattern. The HD 5 Line Raster modality was selected, and the rotation was adjusted for $30^{\circ}$ intervals. Finally, a series of six radial SD-OCT scans, each separated by $30^{\circ}$ and centred on the fovea, were performed. Each raster scan covered a nominal 6-mm square grid area centred on the fovea (Fig. 1). SD-OCT scans were performed between 3:00 and 7:00 p.m. to limit the potential confounding influence of diurnal variations in CT $[36,37]$. All SD-OCT scans were reviewed for image quality, with a signal strength indicator value $\geq 7$. Images were excluded under the following conditions: signal strength less than 7 , motion artefact, involuntary saccade, obvious decentration misalignment, or algorithm segmentation failure due to unclear boundaries between the retina layers.

Three concentric circles centred on the fovea were applied once the tomography map was obtained. This divided the macula into three sub-fields: the central foveal zone (diameter $=1 \mathrm{~mm}$ ), the parafoveal zone (diameter $=3 \mathrm{~mm}$ ), and the perifoveal zone (diameter $=6 \mathrm{~mm}$ ). The radial scan divided the three concentric circles into nine parts, i.e., the central fovea and the temporal, nasal, inferior, and superior regions of the parafovea and the perifovea (Fig. 1).

Following image acquisition at each follow-up visit, all SD-OCT images exported from the instrument were analysed using custom-written software [38]. The software included correction of the image magnification based on the refractive power and was used to quantify
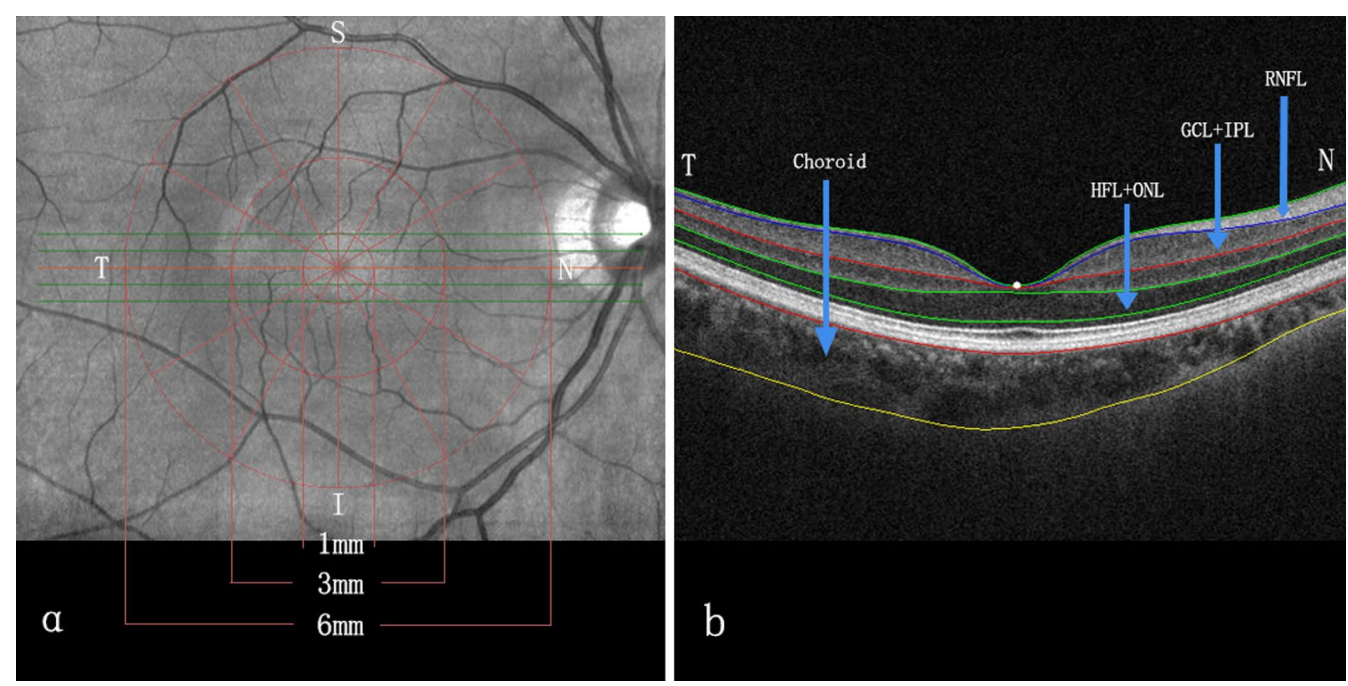

Fig. 1 Cross-sectional and en face segmentation of choroidal and retinal thickness measurements obtained by SD-OCT. a The macula was divided into nine parts: the central fovea and the temporal, nasal, inferior, and superior regions of the parafovea and perifovea. The diameter of the central foveal region was $1 \mathrm{~mm}$. The parafoveal region ranged from 1 to $3 \mathrm{~mm}$ from the central foveal region, and the perifoveal region ranged from 3 to $6 \mathrm{~mm}$ from the central foveal region. $\mathbf{b}$ The boundaries of the fundus structure were segmented by an automated algorithm, and the thickness profiles of the macular outer retinal sub-layers and choroid were determined. S, superior; N, nasal; I, inferior; T, temporal; HFL + ONL, Henle fibre layer and outer nuclear layer; GCL + IPL, ganglion cell layer and inner plexiform layer; RNFL, retinal nerve fibre layer 
the thickness of the fundic retinal sub-layers and the choroid, as previously described [39-41]. The standards for the segmentation of each layer were defined according to the International Nomenclature for Optical Coherence Tomography Panel [42]. The average regional thicknesses of the retinal nerve fibre layer (RNFL), ganglion cell layer and the inner plexiform layer (GCL + IPL), Henle fibre layer and outer nuclear layer $(\mathrm{HFL}+\mathrm{ONL})$, total retina, and choroid of each sub-field were measured by customdeveloped software and used to analyse the changes at the 1- and 2-year follow-up visits. An experienced retinal specialist analysed all the images. If automated segmentation errors occurred or resulted in measurement artefacts, manual segmentation was performed.

\section{Statistical analysis}

Statistical analysis was performed using SPSS software version 20.0 (IBM Corp., Armonk, NY, USA). Data for only the right eyes were included for statistical analysis. SER values were calculated as the sphere power + (cylinder power/2). Changes in CT in the different macular regions were calculated as the $\mathrm{CT}$ at baseline minus the $\mathrm{CT}$ at the 2-year follow-up examination. We defined "rapid progression myopia" as increases in myopia $>1.00$ $\mathrm{D}$ during the 2-year follow-up, "stable progression myopia" was defined as increases $\leq 1.00 \mathrm{D}$ during the 2 -year follow-up according to a mean progression of $-1.20 \mathrm{D}$ over 2 years in a clinical study [43].

The parameters were calculated as the means \pm standard deviations for the continuous variables and rates (proportions) for the categorical variables. One-way analysis of variance (ANOVA) was used to test for differences among the PPAL, FPAL, and SVL groups. Repeated measures analysis of variance (RM-ANOVA) was used to test the parameters for differences among the baseline, 1-year follow-up, and 2-year follow-up visits. For multiple measurements, Bonferroni correction was applied for pairwise comparisons. The intergroup differences were tested with independent sample t-tests between sexes and between the 7- to 9-year-old and the 10- to 12-yearold participants. The relationship between the changes in $\mathrm{CT}$ and AL was tested by linear correlation. Factors associated with longitudinal changes in $\mathrm{CT}$ were analysed by multiple regression analysis.

\section{Results}

\section{Patient characteristics}

Of the initial 210 patients enrolled, 30 were lost to followup or had incomplete data, and 12 were excluded due to poor image quality. For the remaining 168 patients, the mean age at baseline was $9.3 \pm 1.1$ years (range, 7 to 12 years), $52.4 \%$ of whom were males (Table 1 ). The baseline SER and AL values of the right eyes were $-2.38 \pm 0.61$ $\mathrm{D}$ (range, -0.75 to $-3.75 \mathrm{D}$ ) and $24.58 \pm 0.72 \mathrm{~mm}$ (range, 22.82 to $26.85 \mathrm{~mm}$ ), respectively. At the 2-year follow-up examination, the changes in the SER and $\mathrm{AL}$ values for the PPAL, FPAL, and SVL groups were $-1.42 \pm 0.69 \mathrm{D}$ and $0.65 \pm 0.26 \mathrm{~mm},-1.48 \pm 0.57 \mathrm{D}$ and $0.65 \pm 0.23 \mathrm{~mm}$, and $-1.61 \pm 0.64 \mathrm{D}$ and $0.70 \pm 0.23 \mathrm{~mm}$, respectively. There were no significant differences among the groups $(\mathrm{F}=0.625, P=0.537$ and $\mathrm{F}=0.041$, $P=0.960)$. The baseline subfoveal CT values for the

Table 1 Baseline data characteristics of the 168 participants and comparison among the PPAL, FPAL, and SVL groups

\begin{tabular}{|c|c|c|c|c|c|}
\hline Parameter $^{\mathrm{a}}$ & Total $(n=168)$ & PPALs $(n=59)$ & FPALs $(n=48)$ & SVLs $(n=61)$ & $P$ \\
\hline Age (years) & $9.3 \pm 1.1$ & $9.2 \pm 1.1$ & $9.4 \pm 1.1$ & $9.2 \pm 1.1$ & 0.472 \\
\hline Male, n (\%) & $88(52.4 \%)$ & $32(54.2 \%)$ & $23(47.9 \%)$ & $33(54.1 \%)$ & 0.849 \\
\hline SER (D) & $-2.38 \pm 0.61$ & $-2.41 \pm 0.68$ & $-2.34 \pm 0.56$ & $-2.39 \pm 0.57$ & 0.852 \\
\hline VA (logMAR) & $0.00 \pm 0.02$ & $0.00 \pm 0.02$ & $-0.01 \pm 0.02$ & $-0.01 \pm 0.03$ & 0.222 \\
\hline $\mathrm{AL}(\mathrm{mm})$ & $24.58 \pm 0.72$ & $24.55 \pm 0.71$ & $24.58 \pm 0.78$ & $24.61 \pm 0.69$ & 0.900 \\
\hline Subfoveal CT $(\mu \mathrm{m})$ & $231.03 \pm 54.04$ & $231.60 \pm 51.84$ & $230.46 \pm 57.36$ & $231.65 \pm 56.77$ & 0.981 \\
\hline $\mathrm{RT}(\mu \mathrm{m})$ & $251.12 \pm 15.91$ & $250.58 \pm 15.15$ & $252.31 \pm 17.11$ & $251.18 \pm 15.73$ & 0.853 \\
\hline$\triangle \mathrm{SER} 1$ (D) & $-1.02 \pm 0.43$ & $-1.08 \pm 0.42$ & $-1.00 \pm 0.37$ & $-0.99 \pm 0.48$ & 0.376 \\
\hline$\triangle \mathrm{SER} 2(\mathrm{D})$ & $-0.47 \pm 0.38$ & $-0.47 \pm 0.36$ & $-0.48 \pm 0.37$ & $-0.45 \pm 0.40$ & 0.923 \\
\hline$\triangle \mathrm{AL} 1(\mathrm{~mm})$ & $0.36 \pm 0.15$ & $0.38 \pm 0.14$ & $0.35 \pm 0.13$ & $0.36 \pm 0.17$ & 0.688 \\
\hline$\triangle \mathrm{AL} 2(\mathrm{~mm})$ & $0.29 \pm 0.13$ & $0.29 \pm 0.12$ & $0.29 \pm 0.13$ & $0.30 \pm 0.13$ & 0.936 \\
\hline$\Delta \mathrm{CT} 1(\mu \mathrm{m})$ & $-7.98 \pm 23.61$ & $-12.01 \pm 25.97$ & $-8.15 \pm 22.06$ & $-3.67 \pm 21.85$ & 0.155 \\
\hline$\Delta \mathrm{CT} 2(\mu \mathrm{m})$ & $-16.64 \pm 25.631$ & $-17.42 \pm 26.45$ & $-13.43 \pm 27.03$ & $-18.46 \pm 23.72$ & 0.578 \\
\hline
\end{tabular}

$P P A L s=$ personalized progressive addition lenses; $F P A L s=$ fixed progressive addition lenses; $S V L s=$ single vision lenses; $n=$ number; $D=$ dioptre; $S E R=$ spherical equivalent of refraction; $\log M A R=$ logarithm of the minimum angle of resolution; $V A=$ visual acuity; $A L=$ axial length; $C T=$ choroidal thickness; $R T=$ retinal thickness ${ }^{a}$ The means \pm standard deviations for age, SER, VA, and AL; $P$ values based on ANOVA. $\triangle \mathrm{SER} 1$, the change of spherical equivalent of refraction in the first year; $\triangle \mathrm{SER} 2$, the change of spherical equivalent of refraction in the second year; $\triangle A L 1$, the change of axial length in the first year; $\triangle A L 2$, the change of axial length in the second year; $\Delta C T 1$, the change of subfoveal choroidal thickness in the first year; $\Delta C T 2$, the change of subfoveal choroidal thickness in the second year 
PPAL, FPAL, and SVL groups were $231.60 \pm 51.84 \mu \mathrm{m}$, $230.46 \pm 57.36 \mu \mathrm{m}$, and $231.65 \pm 56.77 \mu \mathrm{m}$, respectively. After 2 years of follow-up, the CT values for these groups were $202.17 \pm 56.7793 \mu \mathrm{m}, 210.87 \pm 68.29 \mu \mathrm{m}$, and $209.51 \pm 64.98 \mu \mathrm{m}$, respectively. Changes in CT during the first and second year were not significantly different among the three groups $(\mathrm{F}=1.888, P=0.155$ and $\mathrm{F}=0.550, P=0.578$, for the first and second year separately.)

\section{Changes in SER, AL, and retinal and choroidal thickness}

Since there were no significant differences in the changes in SER, AL, or CT values among the groups at the 2-year follow-up visit, the following data were analysed for all 168 patients. During the study period, the SER and $\mathrm{AL}$ values increased significantly, from $-2.39 \pm 0.61$ $\mathrm{D}$ and $24.58 \pm 0.72 \mathrm{~mm}$ at baseline to $-3.88 \pm 0.92 \mathrm{D}$ and $25.24 \pm 0.76 \mathrm{~mm}$ at the 2-year follow-up $(P<0.001$, Table 2). Furthermore, there were significant correlations between the changes in $\mathrm{AL}$ and the changes in SER (first year, $\mathrm{r}=-0.661, \mathrm{~B}=-0.234$ and second year $\mathrm{r}=-0.677, \mathrm{~B}=-0.233$; both $P<0.001$ ).

In the central macula, the baseline retinal thickness was $251.12 \pm 15.91 \mu \mathrm{m}$, which at the 2-year follow-up was increased to $253.47 \pm 15.74 \mu \mathrm{m}$. This retinal thickening was mainly due to the increased thickness of the HFL + ONL, from $88.29 \pm 10.67 \mu \mathrm{m}$ at baseline to $90.16 \pm 10.49 \mu \mathrm{m}$ at the 2-year follow-up $(P<0.001$, Table 2, Fig. 2a-d).

The subfoveal CT at baseline was $231.03 \pm 54.04 \mu \mathrm{m}$ and became thinner at each follow-up visit, decreasing to $206.53 \pm 59.71 \mu \mathrm{m}$ in the second year $(\mathrm{F}=73.358$ $P<0.001)$. The same results were seen in the parafoveal nasal, temporal, superior, inferior, and perifoveal regions. During the 2-year study period, the minimum decrease in CT was $11.20 \pm 38.41 \mu \mathrm{m}$ in the superior perifovea, and the maximum decrease was $24.63 \pm 31.16 \mu \mathrm{m}$ in the central fovea (Table 2, Fig. 2e, f). Annual variation in CT demonstrated that the thinning amount in the second year was significantly greater than that in the first year $(-16.64 \pm 25.63 \mu \mathrm{m}$ vs. $-7.98 \pm 23.61 \mu \mathrm{m}, \mathrm{t}=2.941$, $P=0.004)$.

\section{Factors associated with longitudinal changes in CT in the central fovea}

Changes in subfoveal CT in the first year were significantly and independently correlated with sex, baseline values for age, $\mathrm{AL}$, whole retinal thickness, and baseline subfoveal CT (Table 3). At the 2-year follow-up, more significant thinning of the central foveal choroid was associated with female sex $(\beta=17.258, P=0.001)$, older age $(\beta=-4.411, P=0.049)$, thicker baseline subfoveal CT $(\beta=-0.081, P=0.046)$, and greater elongation

Table 2 Longitudinal parameters of 168 participants at baseline and follow-up visits

\begin{tabular}{|c|c|c|c|c|c|c|}
\hline Parameter, & Baseline & One-year follow-up & Two-year follow-up & $\Delta$ Thickness & $F$ & $P$ \\
\hline SER (D) & $-2.39(-2.75,-2.00)$ & $-3.41(-4.00,-2.87)$ & $-3.88(-4.50,-3.25)$ & - & 798.16 & $<0.001$ \\
\hline $\mathrm{AL}(\mathrm{mm})$ & $24.58(24.04,25.08)$ & $24.94(24.43,25.44)$ & $25.24(24.71,25.71)$ & - & 1113.87 & $<0.001$ \\
\hline Retina $(\mu \mathrm{m})$ & $251.12 \pm 15.91^{\mathrm{a}}$ & $251.09 \pm 16.34^{\mathrm{b}}$ & $253.47 \pm 15.74^{a, b}$ & - & 23.785 & $<0.001$ \\
\hline RNFL $(\mu \mathrm{m})$ & $14.47 \pm 1.96^{\mathrm{a}}$ & $14.93 \pm 2.23^{\mathrm{a}, \mathrm{b}}$ & $14.31 \pm 2.31^{\mathrm{a}}$ & - & 3.652 & 0.027 \\
\hline $\mathrm{GCL}+\mathrm{IPL}(\mu \mathrm{m})$ & $24.34 \pm 5.96$ & $24.31 \pm 5.85$ & $24.63 \pm 6.07$ & - & 1.407 & 0.352 \\
\hline $\mathrm{HFL}+\mathrm{ONL}(\mu \mathrm{m})$ & $88.29 \pm 10.67^{a, b}$ & $90.74 \pm 10.92^{\mathrm{a}}$ & $90.16 \pm 10.49^{b}$ & - & 10.262 & $<0.001$ \\
\hline \multicolumn{7}{|l|}{ Choroid ( $\mu \mathrm{m})$} \\
\hline Central & $231.03 \pm 54.04$ & $223.71 \pm 56.76$ & $206.53 \pm 59.71$ & $24.63 \pm 31.16$ & 66.635 & $<0.001$ \\
\hline Para-N & $197.44 \pm 55.73$ & $190.25 \pm 57.16$ & $175.36 \pm 61.67$ & $22.08 \pm 26.61$ & 81.990 & $<0.001$ \\
\hline Para-T & $241.78 \pm 53.88$ & $229.81 \pm 53.11$ & $216.47 \pm 60.57$ & $24.30 \pm 33.89$ & 58.673 & $<0.001$ \\
\hline Para-S & $233.09 \pm 50.10$ & $228.39 \pm 54.66$ & $214.97 \pm 56.65$ & $18.11 \pm 34.06$ & 32.074 & $<0.001$ \\
\hline Para-l & $236.17 \pm 54.42$ & $228.91 \pm 58.02$ & $212.57 \pm 61.23$ & $23.59 \pm 32.39$ & 59.813 & $<0.001$ \\
\hline Peri-N & $155.47 \pm 49.74$ & $152.75 \pm 50.89$ & $139.12 \pm 52.79$ & $16.35 \pm 22.65$ & 61.377 & $<0.001$ \\
\hline Peri-T & $244.04 \pm 53.80$ & $234.45 \pm 52.27$ & $221.23 \pm 60.11$ & $22.81 \pm 38.93$ & 38.841 & $<0.001$ \\
\hline Peri-S & $232.69 \pm 51.47$ & $231.60 \pm 52.17$ & $221.48 \pm 56.13$ & $11.20 \pm 38.41$ & 11.048 & $<0.001$ \\
\hline Peri-I & $229.81 \pm 53.64$ & $224.72 \pm 54.80$ & $212.03 \pm 59.96$ & $17.77 \pm 31.45$ & 35.879 & $<0.001$ \\
\hline
\end{tabular}

$\triangle T$ Thickness, change in choroidal thickness between the baseline and the 2-year follow-up

$S E R=$ spherical equivalent of refraction; $D=$ dioptre; $A L=$ axial length; $R N F L=$ retinal nerve fibre layer; $G C L+I P L=$ ganglion cell layer and inner plexiform layer; $H F L+O N L=$ Henle fibre layer and outer nuclear layer; $P a r a=$ parafoveal; $P$ Peri= perifoveal; $N=$ nasal; $T=$ temporal; $S=$ superior; $l=$ inferior

${ }^{a, b}$ The same superscript letter indicate a significant difference between the two results after pairwise comparison using Bonferroni correction

'Medians (interquartile range) for SER and AL

${ }^{\mathrm{d}}$ The means \pm standard deviations for RNFL, GCL + IPL, HFL + ONL, retina, and choroid 


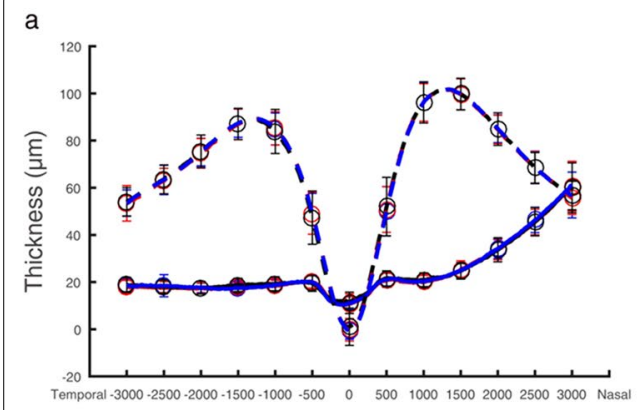

Horizontal distance from fovea $(\mu \mathrm{m})$

C

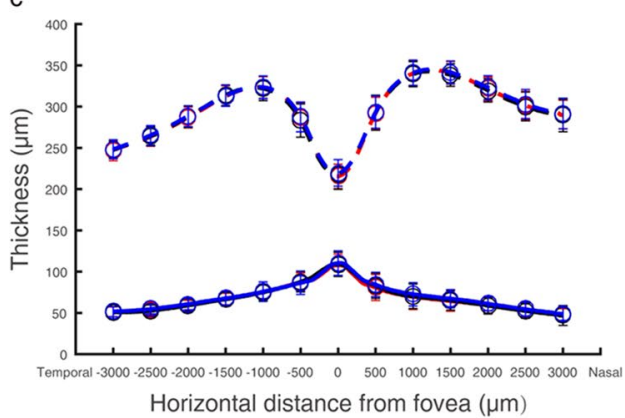

e

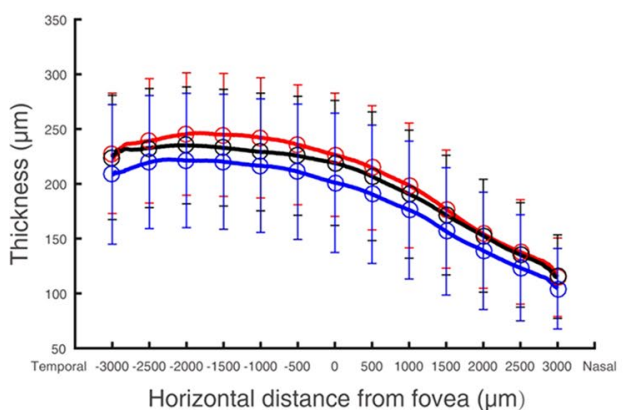

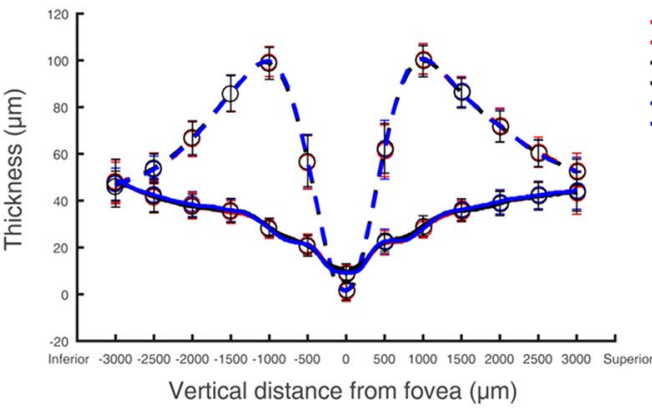

d
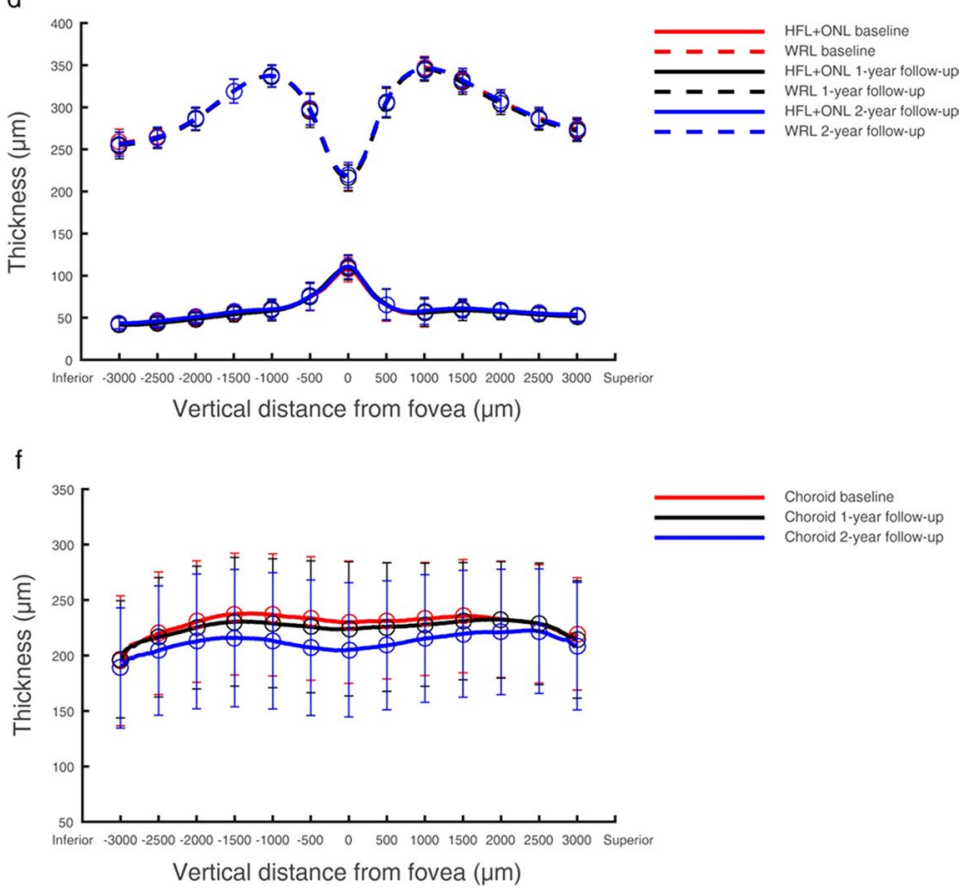

Fig. 2 Thickness profiles of the retina and choroid in 168 myopic children. The thickness profiles of three intra-retinal layers, the total retina, and the choroid in horizontal and vertical scans were obtained by SD-OCT and averaged over each test. Thickness values for the RNFL, GCL + IPL, $\mathrm{HFL}+\mathrm{ONL}$, and WRL were similar; therefore, they overlapped each other in the figure and cannot be seen separately. $\mathbf{a}$, $\mathbf{b}$ Horizontal (left) and vertical (right) thickness profiles of the RNFL and GCL+IPL; $\mathbf{c}$, d horizontal (left) and vertical (right) thickness profiles of the HFL+ONL and whole retina; $\mathbf{e}$, f horizontal (left) and vertical (right) thickness profiles of the choroid. RNFL, retinal nerve fibre layer; GCL+ IPL, ganglion cell layer and inner plexiform layer; HFL + ONL, Henle fibre layer and outer nuclear layer; WRL, whole retinal layer

of the AL $(\beta=-43.579, P=0.002)$. Univariate linear regression analysis revealed significant negative associations between the baseline subfoveal CT and baseline AL (slope $=-17.88, r=-0.241, P=0.002$ ) values and between the 1-year and 2-year changes in the axial length and CT (slope $=-51.79, \mathrm{r}=-0.323$, and $P<0.001$ and slope $=-58.06, \mathrm{r}=-0.434$, and $P<0.001$, respectively).

No significant difference in the baseline subfoveal CT value was found between the sexes (males, $225.59 \pm 51.94 \mu \mathrm{m}$; females, $237.01 \pm 55.97, P=0.172$ ). However, at the 2-year follow-up visit, choroidal thinning was more significant $(P<0.001)$ for females
$(-33.38 \pm 25.49 \mu \mathrm{m})$ than for males $(-16.42 \pm 36.70 \mu \mathrm{m})$. There were no differences in baseline CT between the 7- to 9-year-old and 10- to 12-year-old participants $(P=0.700)$ or in the amount of thinning at the 2-year follow-up $(P=0.989$, Additional file 1: Table S1).

\section{Longitudinal changes in thickness of the retina and choroid in children with rapid progression and stable progression myopia}

Based on the changes in SER at the end of the 2-year study, we divided the children into two groups. For rapid progression, the SER increase was $>1.00 \mathrm{D}(\mathrm{n}=129)$, 
Table 3 Multiple regression analysis of factors associated with 1- and 2-year longitudinal changes in choroidal thickness in the central fovea

\begin{tabular}{|c|c|c|c|c|}
\hline \multirow[t]{2}{*}{ Factor } & \multicolumn{4}{|c|}{ Subfoveal choroidal thickness change $(\mu \mathrm{m})^{\mathrm{a}}$} \\
\hline & One-year $\Delta$ thickness $(95 \% \mathrm{Cl})$ & $P$ & Two-year $\Delta$ thickness $(95 \% \mathrm{Cl})$ & $P$ \\
\hline Age (years) & $-2.36(-5.74$ to 1.01$)$ & 0.168 & $-4.41(-8.81$ to 0.01$)$ & 0.049 \\
\hline Sex & $-16.39(-24.13$ to -8.66$)$ & $<0.001$ & $-17.25(-27.19$ to -7.32$)$ & 0.001 \\
\hline Lens & $-6.62(-14.44$ to 1.18$)$ & 0.096 & $-6.11(-16.02$ to 3.79$)$ & 0.227 \\
\hline Baseline AL (mm) & $-8.87(-14.52$ to -3.21$)$ & 0.002 & $-5.11(-12.30$ to 2.07$)$ & 0.163 \\
\hline Baseline SER (D) & $-1.78(-7.66$ to 4.09$)$ & 0.355 & $2.96(-4.48$ to 10.40$)$ & 0.435 \\
\hline Baseline whole retinal thickness $(\mu \mathrm{m})$ & $-0.25(-0.46$ to 0.03$)$ & 0.024 & $-0.19(-0.47$ to 0.07$)$ & 0.158 \\
\hline Baseline subfoveal choroidal thickness $(\mu \mathrm{m})$ & $-0.06(-0.12$ to 0.01$)$ & 0.040 & $-0.08(-0.16$ to -0.001$)$ & 0.046 \\
\hline One-year AL change (mm) & $-49.66(-79.68$ to -19.64$)$ & 0.001 & & \\
\hline Two-year AL change (mm) & & & $-43.58(-71.41$ to -15.74$)$ & 0.002 \\
\hline One-year SER change (D) & $4.86(-5.22$ to 14.95$)$ & 0.345 & & \\
\hline Two-year SER change (D) & & & $9.08(-1.07$ to 19.23$)$ & 0.080 \\
\hline
\end{tabular}

$C l=$ confidence interval; $A L=$ axial length; $S E R=$ spherical equivalent of refraction

${ }^{\text {a }} \Delta$ Thickness changes are based on estimates determined by regression analysis; lens includes three groups of lenses worn by the participants: personalized progressive addition lenses (PPALs), fixed progressive addition lenses (FPALs), and single vision lenses (SVLs)

and for stable progress, the SER increase was $\leq 1.00 \mathrm{D}$ $(\mathrm{n}=39)$. There were no significant differences in the baseline age, sex, SER, AL, or CT between the two groups (Additional file 1: Table S2). The AL in the two groups increased from $24.58 \pm 0.73 \mathrm{~mm}$ and $24.55 \pm 0.72 \mathrm{~mm}$ at baseline to $25.33 \pm 0.75 \mathrm{~mm}(\mathrm{~F}=1311.30, P<0.001)$ and $24.97 \pm 0.76 \mathrm{~mm}(\mathrm{~F}=2227.26, P<0.001)$ at the 2 -year follow-up. The choroid in the rapid progression group continued to thin during the 2-year follow-up visits $(\mathrm{F}=92.06, P<0.001$, Fig. 3$)$. However, there was no significant difference in the change in $\mathrm{CT}$ during this 2-year study in the stable progression group $(\mathrm{F}=2.23, P=0.119)$.

\section{Discussion}

Previous studies have shown that $\mathrm{CT}$ is correlated with refractive error and the AL and it is thinner in myopes than in hyperopes $[25,30]$. However, the characteristics of retinal and choroidal thickness changes in myopic schoolchildren have not been clearly described. This longitudinal study included a large sample of myopic children to observe the morphological changes in retinal and choroidal thickness that correlated with changes in SER and AL over 2 years. There are three new important findings in this study. First, the macular CT of myopic children became thinner during the 2-year followup. Thinning was evident not only in the central fovea but also in the parafoveal and perifoveal regions. Second, thinning of the choroid occurred principally in the rapid progression group but not in the stable progression group. Third, the main influencing factors of CT in myopic children were axial growth and sex.
In this 2-year randomized controlled clinical study, personalized additional designed lenses did not produce a significant myopia control effect. This could indicate that the effect of near addition lenses on myopia control is limited [44, 45]. There was no significant difference in the change in CT between the three groups during this 2-year study. However, in general, the CT significantly decreased in the nine macular sectors of the Early Treatment Diabetic Retinopathy Study grid. Furthermore, CT was increasingly attenuated in the rapid progression group but not in the stable group, indicating that $\mathrm{CT}$ is continuously thinning in progressive myopia. This was consistent with the study conducted by Jin et al. [28], while not with the study by Xiong et al., who found a marked decrease in the CT for newly developed myopes but not in persistent myopes [29]. In European children with greater increases in AL, Hansen et al. [27] found that $\mathrm{CT}$ increased less or even became thinner. The varying outcomes can be attributed to factors such as different ethnicities, age, and refractive status. Taken together, we think that the thinning of $\mathrm{CT}$ and the decreasing choroidal blood perfusion, can cause scleral hypoxia, and may indicate the onset or faster progression of myopia.

Several studies have reported the correlation of CT with $\mathrm{AL}$ in children. In a cross-sectional study of 8- to 11-year-old myopic children, Qi et al. found that each millimetre of increase in AL was correlated with a reduction of $18.95 \mu \mathrm{m}$ in subfoveal CT [25]. Additionally, Xiong et al. found that a $1-\mathrm{mm}$ increase in AL was accompanied by a $26.66-\mu \mathrm{m}$ decrease in the thickness of the choroid [29]. Our current study found that for each $1-\mathrm{mm}$ increase in AL during the first year, CT decreased 

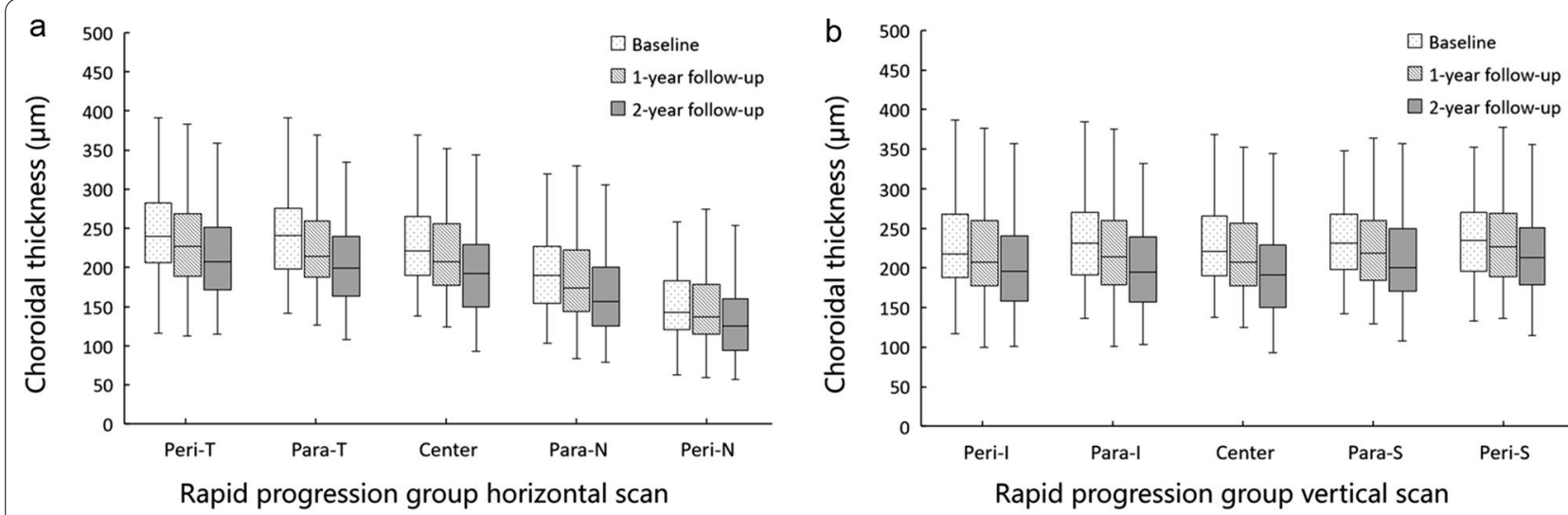

C

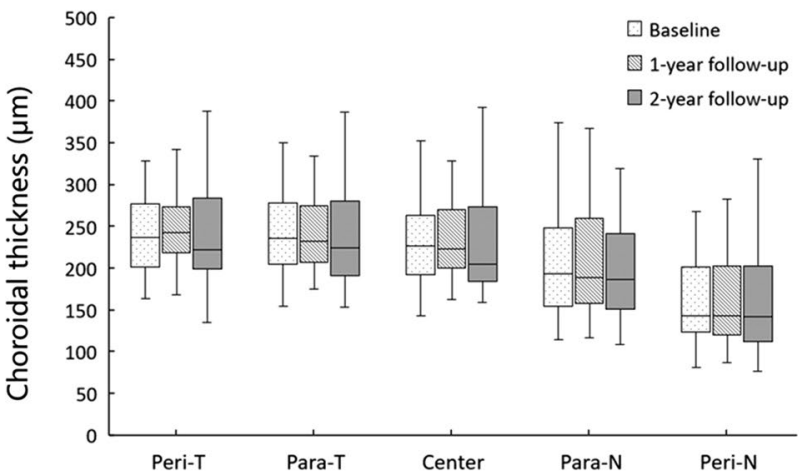

d

Stable progression group horizontal scan

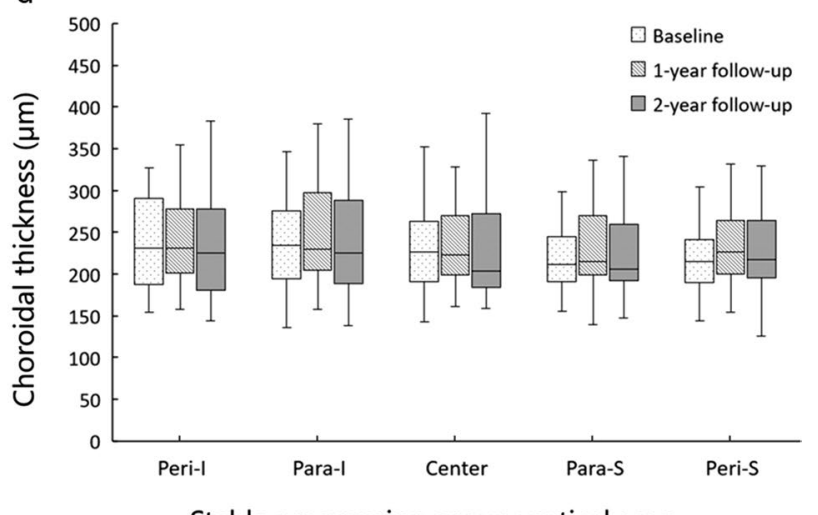

Stable progression group vertical scan

Fig. 3 Longitudinal changes of fundic choroidal thickness in the central, parafoveal, and perifoveal regions of the rapid and stable progression groups. $\mathbf{a}, \mathbf{b}$ Average choroidal thickness in horizontal and vertical scans of the rapid progression group. $\mathbf{c}, \mathbf{d}$ Average choroidal thickness in horizontal and vertical scans of the stable progression group. Peri, perifoveal; Para, parafoveal; T, temporal; N, nasal; I, inferior; S, superior

$51.79 \mu \mathrm{m}$, and for the second year, the decrease was $64.56 \mu \mathrm{m}$. Additionally, the progression of refractive error and increases in AL in our study were larger than those reported by others $[28,29]$. The larger decreases in CT that we found can be attributed to the fact that this was the first 2-year longitudinal study focused on school-aged children with simple low-to-moderate myopia. In addition, we found that the change in CT during the first year was smaller compared to the second year, although the difference of AL change was not so obvious. We believe that the change of $\mathrm{CT}$ during the myopic progression was not entirely due to the passive stretch thinning caused by the expansion of the vitreous chamber. There is also other active mechanism which adjusts the input of visual information [46].

Two other factors that influenced CT were sex and age. Several studies have shown no difference in CT between male and female children [20, 47, 48], and our results are consistent. However, at the 2-year follow-up, the thinning of the choroid of female participants was significantly greater than that of the male participants.
The specific reasons for this sex difference need to be further studied. The relationship between $\mathrm{CT}$ and age was confused by the different degrees of SER and the different myopia progression. Therefore, the results of previous studies are inconsistent. Xiong et al. confirmed that CT was positively correlated with age for emmetropes and mild myopes but not for children with SERs $\leq 2.00 \mathrm{D}$ [26]. Our study found that there was no difference in CT changes between the two age groups. This may be related to our narrow age group (7 to 12 years old) and similar distribution of dioptres (of which $79.2 \%$ were $\leq 2.00 \mathrm{D}$ ).

There are some limitations to our study. First, this study was a part of PACT [31]. Even though the results showed no significant differences in the SER, AL, and CT values among three groups (two treatment groups and one control group), our data cannot completely rule out the effect of different myopia control lenses on CT. The second limitation is that we did not analyse the role of growth and systemic development (i.e., changes in body height, weight, and puberty), in the changes in CT. The 
third was that we only observed myopia progression for 2 years.

\section{Conclusions}

The macular CT of myopic children, especially those with rapid progression myopia, was significantly attenuated at the 1- and 2-year follow-up visits. Therefore, it suggests an association between CT thinning and myopia progression and axial elongation. The control of CT may play an important role in the regulation of children ocular growth.

\section{Supplementary Information}

The online version contains supplementary material available at https://doi. org/10.1186/s40662-022-00276-4.

Additional file 1: Table S1. Longitudinal changes in ocular biological parameters stratified by sex and age. Table S2. Comparison of baseline data between the rapid progression and stable progression groups.

\section{Acknowledgements}

The authors thank Shenghai Huang, Ce Shi, Binjun Zhang at the Eye Hospital and School of Ophthalmology and Optometry, Wenzhou Medical University, for their collaboration on this study.

\section{Authors' contributions}

$M X, J B$, and JQ designed the study. XY, MW and JZ performed the study. MW and MS managed the data. KF, HC, and BD analysed and interpreted the data. MX and $X Y$ wrote the initial draft. JB and JQ revised the manuscript. All the authors provided a final review. All authors read and approved the final manuscript.

\section{Funding}

This work was supported by the Zhejiang Provincial Key Research and Development Program (Grant No. 2021C03102), International S\&T Cooperation Program of China (Grant No. 2014DFA30940), with partial funding provided by Essilor International S.A. and Zhejiang Provincial Natural Science Foundation of China (Grant No. LY19H120004).

\section{Availability of data and materials}

The datasets used and analysed in our study are available upon reasonable request from the corresponding author.

\section{Declarations}

Ethics approval and consent to participate

This study was approved by the Institutional Review Board of the Eye Hospital of Wenzhou Medical University (KYK [2013] 34).

\section{Consent for publication}

Not applicable.

\section{Competing interests}

Jia Qu is the editor in chief of the journal. The other authors have no competing interests.

\section{Author details}

${ }^{1}$ Eye Hospital and School of Ophthalmology and Optometry, Wenzhou Medical University, Wenzhou, Zhejiang, China. ${ }^{2}$ National Clinical Research Center for Ocular Diseases, Wenzhou, Zhejiang, China. ${ }^{3}$ WEIRC, WMU-Essilor International Research Centre, Wenzhou, Zhejiang, China. ${ }^{4}$ R\&D Vision Sciences AMERA, Essilor International, Singapore, Singapore.
Received: 26 August 2021 Accepted: 10 January 2022

Published online: 01 February 2022

\section{References}

1. Cheng CY, Hsu WM, Liu JH, Tsai SY, Chou P. Refractive errors in an elderly Chinese population in Taiwan: the Shihpai eye study. Invest Ophthalmol Vis Sci. 2003:44(11):4630-8.

2. Ding BY, Shih YF, Lin LLK, Hsiao CK, Wang IJ. Myopia among schoolchildren in East Asia and Singapore. Surv Ophthalmol. 2017;62(5):677-97.

3. Holden BA, Fricke TR, Wilson DA, Jong M, Naidoo KS, Sankaridurg P, et al. Global prevalence of myopia and high myopia and temporal trends from 2000 through 2050. Ophthalmology. 2016;123(5):1036-42.

4. Zhu X, Wallman J. Temporal properties of compensation for positive and negative spectacle lenses in chicks. Invest Ophthalmol Vis Sci. 2009;50(1):37-46.

5. Wallman J, Wildsoet C, Xu A, Gottlieb MD, Nickla DL, Marran L, et al. Moving the retina: choroidal modulation of refractive state. Vision Res. 1995:35(1):37-50.

6. Lu F, Zhou X, Jiang L, Fu Y, Lai X, Xie R, et al. Axial myopia induced by hyperopic defocus in guinea pigs: a detailed assessment on susceptibility and recovery. Exp Eye Res. 2009;89(1):101-8.

7. Hung LF, Wallman J, Smith EL 3rd. Vision-dependent changes in the choroidal thickness of macaque monkeys. Invest Ophthalmol Vis Sci. 2000;41(6):1259-69.

8. Kim DY, Silverman RH, Chan RV, Khanifar AA, Rondeau M, Lloyd H, et al. Measurement of choroidal perfusion and thickness following systemic sildenafil (Viagra $\left.\left({ }^{\circledR}\right)\right)$. Acta Ophthalmol. 2013;91(2):183-8.

9. Okamoto M, Matsuura T, Ogata N. Choroidal thickness and choroidal blood flow after intravitreal bevacizumab injection in eyes with central serous chorioretinopathy. Ophthalmic Surg Lasers Imaging Retina. 2015:46(1):25-32.

10. Junghans BM, Crewther SG, Liang H, Crewther DP. A role for choroidal lymphatics during recovery from form deprivation myopia? Optom Vis Sci. 1999;76(11):796-803.

11. Nickla DL, Wallman J. The multifunctional choroid. Prog Retin Eye Res. 2010;29(2):144-68.

12. Agrawal R, Gupta P, Tan KA, Cheung CM, Wong TY, Cheng CY. Choroidal vascularity index as a measure of vascular status of the choroid: measurements in healthy eyes from a population-based study. Sci Rep. 2016;6:21090.

13. Wu H, Xie Z, Wang P, Liu M, Wang Y, Zhu J, et al. Differences in retinal and choroidal vasculature and perfusion related to axial length in pediatric anisomyopes. Invest Ophthalmol Vis Sci. 2021;62(9):40.

14. Zhang S, Zhang G, Zhou X, Xu R, Wang S, Guan Z, et al. Changes in choroidal thickness and choroidal blood perfusion in guinea pig myopia. Invest Ophthalmol Vis Sci. 2019;60(8):3074-83.

15. Zhou X, Zhang S, Zhang G, Chen Y, Lei Y, Xiang J, et al. Increased choroida blood perfusion can inhibit form deprivation myopia in guinea pigs. Invest Ophthalmol Vis Sci. 2020;61(13):25.

16. Zhao F, Zhang D, Zhou Q, Zhao F, He M, Yang Z, et al. Scleral HIF-1alpha is a prominent regulatory candidate for genetic and environmental interactions in human myopia pathogenesis. EBioMedicine. 2020;57: 102878

17. Bez D, Megreli J, Bez M, Avramovich E, Barak A, Levine H. Association between type of educational system and prevalence and severity of myopia among male adolescents in Israel. JAMA Ophthalmol. 2019;137(8):887-93

18. Bao J, Drobe B, Wang Y, Chen K, Seow EJ, Lu F. Influence of near tasks on posture in myopic Chinese schoolchildren. Optom Vis Sci. 2015;92(8):908-15.

19. Fontaine M, Gaucher D, Sauer A, Speeg-Schatz C. Choroidal thickness and ametropia in children: a longitudinal study. Eur J Ophthalmol. 2017:27(6):730-4

20. Bidaut-Garnier M, Schwartz C, Puyraveau M, Montard M, Delbosc B, Saleh M. Choroidal thickness measurement in children using optical coherence tomography. Retina. 2014;34(4):768-74.

21. Li XQ, Munkholm A, Larsen M, Munch IC, Copenhagen Child Cohort Study G. Choroidal thickness in relation to birth parameters in 11- to 
12-year-old children: the Copenhagen child cohort 2000 eye study. Invest Ophthalmol Vis Sci. 2014;56(1):617-24.

22. Li XQ, Jeppesen P, Larsen M, Munch IC. Subfoveal choroidal thickness in 1323 children aged 11 to 12 years and association with puberty: the Copenhagen child cohort 2000 eye study. Invest Ophthalmol Vis Sci. 2014;55(1):550-5.

23. Nagasawa T, Mitamura Y, Katome T, Shinomiya K, Naito T, Nagasato D, et al. Macular choroidal thickness and volume in healthy pediatric individuals measured by swept-source optical coherence tomography. Invest Ophthalmol Vis Sci. 2013;54(10):7068-74.

24. Ruiz-Moreno JM, Flores-Moreno I, Lugo F, Ruiz-Medrano J, Montero JA, Akiba M. Macular choroidal thickness in normal pediatric population measured by swept-source optical coherence tomography. Invest Ophthalmol Vis Sci. 2013;54(1):353-9.

25. Qi Y, Li L, Zhang F. Choroidal thickness in Chinese children aged 8 to 11 years with mild and moderate myopia. J Ophthalmol. 2018;2018:7270127.

26. Xiong S, He X, Deng J, Lv M, Jin J, Sun S, et al. Choroidal thickness in 3001 Chinese children aged 6 to 19 years using swept-source OCT. Sci Rep. 2017;7:45059

27. Hansen MH, Li XQ, Larsen M, Olsen EM, Skovgaard AM, Kessel L, et al. Fiveyear change in choroidal thickness in relation to body development and axial eye elongation: the CCC2000 eye study. Invest Ophthalmol Vis Sci. 2019;60(12):3930-6.

28. Jin P, Zou H, Xu X, Chang TC, Zhu J, Deng J, et al. Longitudinal changes in choroidal and retinal thicknesses in children with myopic shift. Retina. 2019;39(6):1091-9.

29. Xiong S, He X, Zhang B, Deng J, Wang J, Lv M, et al. Changes in choroidal thickness varied by age and refraction in children and adolescents: a 1-year longitudinal study. Am J Ophthalmol. 2020;213:46-56.

30. Read SA, Collins MJ, Vincent SJ, Alonso-Caneiro D. Choroidal thickness in myopic and nonmyopic children assessed with enhanced depth imaging optical coherence tomography. Invest Ophthalmol Vis Sci. 2013;54(12):7578-86.

31. Yu X, Zhang B, Bao J, Zhang J, Wu G, Xu J, et al. Design, methodology, and baseline data of the personalized addition lenses clinical trial (PACT). Medicine. 2017;96(11): e6069.

32. Hashemi $\mathrm{H}$, Asharlous $\mathrm{A}$, Khabazkhoob M, Iribarren R, Khosravi A, Yekta $A$, et al. The effect of cyclopentolate on ocular biometric components. Optom Vis Sci. 2020;97(6):440-7.

33. Bahar A, Pekel G. The effects of pharmacological accommodation and cycloplegia on axial length and choroidal thickness. Arq Bras Oftalmol. 2021:84(2):107-12.

34. Ozcaliskan S, Yenerel NM. The effect of cycloplegia on biometric measurements using swept-source optical coherence tomography-based biometry. Clin Exp Optom. 2019;102(5):501-5.

35. Huang F, Huang S, Xie R, Yang Y, Yan J, Cao X, et al. The effect of topical administration of cyclopentolate on ocular biometry: an analysis for mouse and human models. Sci Rep. 2017;7(1):9952.

36. Chakraborty R, Read S, Collins M. Diurnal variations in axial length, choroidal thickness, intraocular pressure, and ocular biometrics. Invest Ophthalmol Vis Sci. 2011;52(8):5121-9.

37. Tan CS, Ouyang Y, Ruiz H, Sadda SR. Diurnal variation of choroidal thickness in normal, healthy subjects measured by spectral domain optical coherence tomography. Invest Ophthalmol Vis Sci. 2012;53(1):261-6.

38. Liu X, Shen M, Yuan Y, Huang S, Zhu D, Ma Q, et al. Macular thickness profiles of intraretinal layers in myopia evaluated by ultrahigh-resolution optical coherence tomography. Am J Ophthalmol. 2015;160(1):53-61.e2.

39. Savini G, Barboni P, Parisi V, Carbonelli M. The influence of axial length on retinal nerve fibre layer thickness and optic-disc size measurements by spectral-domain OCT. Br J Ophthalmol. 2012;96(1):57-61.

40. Kang SH, Hong SW, Im SK, Lee SH, Ahn MD. Effect of myopia on the thickness of the retinal nerve fiber layer measured by Cirrus HD optical coherence tomography. Invest Ophthalmol Vis Sci. 2010;51 (8):4075-83.

41. Nowroozizadeh S, Cirineo N, Amini N, Knipping S, Chang T, Chou T, et al. Influence of correction of ocular magnification on spectral-domain OCT retinal nerve fiber layer measurement variability and performance. Invest Ophthalmol Vis Sci. 2014;55(6):3439-46.

42. Staurenghi G, Sadda S, Chakravarthy U, Spaide RF, International Nomenclature for Optical Coherence Tomography Panel. Proposed lexicon for anatomic landmarks in normal posterior segment spectral-domain optical coherence tomography: the IN • OCT consensus. Ophthalmology. 2014;121(8):1572-8.

43. Chua WH, Balakrishnan V, Chan YH, Tong L, Ling Y, Quah BL, et al. Atropine for the treatment of childhood myopia. Ophthalmology. 2006;113(12):2285-91.

44. Bao J, Wang Y, Zhuo Z, Yang X, Tan R, Drobe B, et al. Influence of progressive addition lenses on reading posture in myopic children. $\mathrm{Br} J$ Ophthalmol. 2016;100(8):1114-7.

45. Gwiazda J, Hyman L, Hussein M, Everett D, Norton TT, Kurtz D, et al. A randomized clinical trial of progressive addition lenses versus single vision lenses on the progression of myopia in children. Invest Ophthalmol Vis Sci. 2003;44(4):1492-500.

46. Vincent SJ, Collins MJ, Read SA, Carney LG. Retinal and choroidal thickness in myopic anisometropia. Invest Ophthalmol Vis Sci. 2013;54(4):2445-56.

47. He X, Jin P, Zou H, Li Q, Jin J, Lu L, et al. Choroidal thickness in healthy Chinese children aged 6 to 12: the Shanghai children eye study. Retina. 2017;37(2):368-75.

48. Jin P, Zou H, Zhu J, Xu X, Jin J, Chang TC, et al. Choroidal and retinal thickness in children with different refractive status measured by swept-source optical coherence tomography. Am J Ophthalmol. 2016;168:164-76.

\section{Publisher's Note}

Springer Nature remains neutral with regard to jurisdictional claims in published maps and institutional affiliations.

Ready to submit your research? Choose BMC and benefit from

- fast, convenient online submission

- thorough peer review by experienced researchers in your field

- rapid publication on acceptance

- support for research data, including large and complex data types

- gold Open Access which fosters wider collaboration and increased citations

- maximum visibility for your research: over $100 \mathrm{M}$ website views per year

At BMC, research is always in progress.

Learn more biomedcentral.com/submissions 